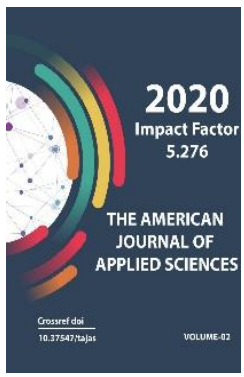

\title{
Semantics Of Phytomorph Metafores Classification
}

\author{
Gulnora Mukimova Rashidovna \\ Independent Researcher, Department Of Uzbek Linguistics, Bukhara State University, \\ Bukhara, Uzbekistan
}

\footnotetext{
Journal Website: http://usajournalshub.c om/index,php/tajas

Copyright: Original content from this work may be used under the terms of the creative commons attributes 4.0 licence.
}

\section{ABSTRACT}

The article is based on factual material that metaphors are an important product of folk thinking, one of the most common ways of generating portable meaning. The fact that phytomorphic metaphors, which are words based on plant names in the Uzbek language, occur as a separate system is proved by examples. They are divided into two groups according to their spiritual-descriptive expression, that is, analyzed and classified as positive and negative metaphors.

\section{KEYWORDS}

Metaphor, phytometaphor, anthropomorphic, zoomorphic, phytomorphic, cosmorphic,abiomorphic, linguoculturological, linguistic-poetic, myths, animism.

\section{INTRODUCTION}

The word metaphor belongs to the Greek language, and its original lexical meaning is to move. It is the most active of the phenomena of the occurrence of derivative meaning. Apparently, the derivation of derivative meaning is based on the similarity of the generative and derivative semantic references [4,94-b]. This phenomenon of language has long been of interest to people, and theoretical views on it have been formed since ancient times. A metaphor is a mechanism of speech in which the denotation of a lexeme is 
used to express another meaning based on its external, apparent similarity [7,100-p].

\section{LITERATURE REVIEW}

According to linguist R. Kungurov, metaphor is a hidden analogy. "But it is different from a simple analogy," he writes.

If a simple analogy always consists of two main parts (that is, the object being compared and compared), only the second member remains in the metaphor, the analogy is omitted, but it is clear from the context, so the object described in the metaphor is through this second member, is perceived "[p. 9.54].

Metaphor is one of the most common ways of creating portable meaning. The skillful use of metaphor in works of art depends on the writer's artistic thinking. There are many manifestations of metaphor in language. Its species are anthropomorphic, zoomorphic, phytomorphic, cosmomorphic and abiomorphic metaphor.

Phytomorphic metaphor is a linguistic phenomenon associated with the figurative origin of plant names and their properties.

\section{ANALYSIS}

Phytonym metaphors in the Uzbek language can be analyzed and classified as positive and negative metaphors according to their spiritual and descriptive expression.

1. Phytometaphors that express a positive meaning. Examples of such phytonims are bo'tako'z, gul, mehrigiyo, ra'no, sarv. For example, the original lexical meaning of the common Turkish word bo'tako'z is an annual weed with purple or blue flowers belonging to the family of intricate flowers [O'TIL, I, 45-p.], it is applied in a figurative sense to a person with a beautiful eye, a wide eye, and such eyes:
The buckwheat who was talking about chanson, You're the only one who's better than others. ("White apple, red apple"); Well done to the girl you got, Congratulations, buckwheat eyes! (“Gulnorpari”).

Note that the word is used figuratively for a lover, a child, and a loved one. The eye of these is like the beautiful and lovable eye of a camel child. Some people even gave her the name Bo'tako'z, intending to make her eyes water. Such naming is more common in camelrelated populations in most places.

Another of the phytometaphors that express the positive meaning mentioned above is the Persian gul(flower) lexeme, which is called chechak in the ancient Turkic language and some modern Turkic languages, including Turkish. The Explanatory Dictionary of the Uzbek Language defines the word gul(flower) as follows: For example, like an apple flower, a pear flower. Example: Cherries are blooming in Nuri's yard. Their white, beautiful flowers glow very elegantly in the sunlight. [Oybek, Selected works.]

The flower phytonym is the most active lexeme that forms positive semen towards humans. If we look at the works of poets and writers, in the Uzbek folklore and fiction it is often observed that the flower phytonim is represented by a lover. But in some cases it is less common to use it in a figurative sense, the best, the best of the young. For example, the flower of the young man(yigitning guli), the flower of the intelligentsia(ziyolilarning guli). In the flower combination of the young man, the phyton of the flower is the most beautiful, energetic, handsome young man among the young men, and in the flower combination of the intelligentsia, he is the most knowledgeable among the intellectuals. Here are some examples of the incense burner coming in the figurative sense; the best of these metaphors: 
- The king girl, the sugar girl, the flower of the girls, Show your eyebrows, I am its slave. [S. Exactly, Doxunda].

- The young man knew the purpose of the bride and groom, and although he knew their destination, he greeted them and said to himself: Yes, young man's flower, where are you going? [T. Malik, Ajab dunyo].

- Spring season. Fifty years of my neighbor Ghafur Ghulam. At that time, Bulbul Mamedov was the flower of the wedding. [H. Nazir, Maftuningman, Azerbaijan].

The flower lexeme is often used in the sense of a beloved woman, referring to a lover, represented by a first-person possessive suffix. Example: My flower, I have something to say to you. You did not reply to my letter, you are my sweetheart and my spring, Gulbahor. [M. Alaviya].

In our language, the original lexical meaning of the lexeme mehrigiyo, which has a positive character according to the spiritual-descriptive expression of phytonim metaphors, is a perennial plant belonging to the family Ituzumgulli [OTIL, II, p. 588]. There is a legend among the people that people will love the person who keeps this plant grain next to him. The word is used figuratively to refer to someone or something that attracts affection.

For example, she gave birth to a son, and the couple fell in love. [S. Ahmad, Desert Winds]. It is said that a good man has love. [S. Karomatov, Golden Sand].

The phytonym Mehrigiyo is mainly used in a figurative sense to express positive relationships between people. It is no exaggeration to say that this phytonym metaphor fully reflects our national culture, moral traditions and customs. It is obvious that the basis of our nationality is love, which is love for parents, the Motherland, the child, which is the most noble quality for our people.
This aspect is also reflected in the following sentence: The Uzbek people have a special kindness that attracts people of other nationalities. (From the newspaper)

Another phytometaphora that has a positive meaning is the Arabic word ra'no, whose lexical meaning is a perennial plant belonging to the rose family [OTIL, III, p. 359]. The word is used in a figurative sense to refer to beautiful, attractive women. Example: The burning of a rano in his work gave the chaman an incomparable perfection. [M. Ikrom]. "It's not an exaggeration of mine," said Anwar. "For example, you are next to flowers now, and you are really a bouquet of flowers." [A. Qodiriy, Mehrobdan chayon].

It should be noted that the use of this phytonym metaphor in this figurative sense, mainly in fiction, is almost non-existent in oral speech.

\section{DISCUSSION}

Sarv is one of the most widely used symbols in Uzbek classical poetry. In Arabic, the lexical meaning of this word is a cone-shaped, coniferous tree species belonging to the family of conifers [OTIL, III, p. 447]. This tree grows mainly in southern countries, and its peculiarity is that the needle-like leaf is always green and erect.

Sarv phytonim is used in fiction in a figurative sense to refer to tall, well-built, graceful women.

Consider the following example:

O'tkali ul sarvi gulrux soridin,

Yo'q xabar ul sarvi gul ruxsoridin.

Hajridin bog' ichra berur yodima

Qomatidin sarvi, gul ruxsoridin.

This poem is taken from Alisher Navoi's "Badoe ul-vasat", in which the poet used the phytonym cypress as two types of nomads. In 
the first and second verses, the poet metaphorizes the word by expressing the mistress through the word cypress. It is clear that the poet embodied the art of metaphor in this place. In the fourth verse, the poet likens the statue of a mistress to a cypress tree and creates the art of tashbih.

In Uzbek traditions, the maple tree is revered as a symbol of strength, patience, and wisdom, while in Uzbek traditions, the maple tree is a symbol of longevity, wisdom, and courage: the maple tree is about a tall man; great as a plane tree - about old people.

Sycamore is actually a Persian word, and in the dictionary it is given as a large tree with a long bark, blue bark, clawed leaves. The sycamore does not rot, the juniper does not wither. Proverbs.

- The cabbage is clean, watered and clean. Sarhovuz .. plane trees reaching to the sky .. "Nurali". The phytonym of sycamore comes in the sense of a portable spouse or son, a child, of course, in relation to a woman. Find your sycamore in the beauty bar. Proverbs. You were the fetish on my neck, you were the sycamore tree that grew before me. "Oysuluv".

The term sycamore is also used to refer to a supportive person who is supportive in times of distress. It should be noted that the characteristics inherent in the sycamore tree, such as durability, longevity and vigor, have been transferred to human qualities through metaphor. [Turdikulov] has sycamores in the area. "Youth".

\section{Phytonym metaphors that express negative meaning.}

The lexicon of the Uzbek language is rich and unique, its vocabulary is enriched with words with positive meanings, as well as phytonym metaphors with negative meanings. An example of such metaphors is the phytonym alfalfa. The word alaf is Persian according to its historical etymological layer, and its lexical meaning is grass. The word alaf is used in a figurative sense to refer to something generally ugly, naughty person or thing. Example: A brain full of foul grass needs to be cleansed. "Fist." I would kill the tyrant a hundred times. I would pull that stinking weed out of the garden of life, withering it. Uyg'un.

It is known that the word yosuman is called yosmin, jasmine in Persian, and it has a lexical meaning of a fragrant, white, yellow, blue ball flower ornamental shrub. [OTIL, II, p. 49] The word yosuman is used in a figurative sense to refer to cunning, cunning women, and is a negative character who is a symbol of cunning in folklore and written literature. Yosuman is usually pure people with deception, cunning; between a girl and a father, a mother and a son, a lover and a mistress. For example, in Alisher Navoi's epic "Farhod and Shirin", Yosuman tricked the invincible Farhod and brought him to Hisrav. Jasmine is also referred to in legends, fairy tales and epics as a witch, cunning, wily, sly old woman [9, 89p].

Another phytonym metaphor that has a negative connotation that is widely used in the literary text is the thorn. The original meaning of this plant in the dictionary is that the stem is a weed that grows on the ground and its star-shaped thorn, which in a figurative sense refers to those who obstruct someone's path and harm him. Example: Now I see that I was thorn, and as Goziddin Kobulov tried to pull me away, I began to wave his hand. [O. Mukhtorov, Egilgan, bosh].

In the above sentence, the phytomorph of the thorn, in a negative sense, reveals a flaw inherent in man as a whole image, that the property of harming the human body is transferred to the image through metaphor.

Another phytomorphic metaphor that has a negative connotation is shumgiya. The lexical meaning of this plant, which is less active in our oral speech, is a free-spirited weed that 
feeds on the roots of other crops, a person who lives for his own benefit and at the expense of others; the pest man comes figuratively. Example: Let's uproot the holes in our path in their place without allowing them to take root! Only then will we reach the bright destination of our hearts without any worries. From the newspaper.

The level of use of this word in a figurative sense is not high in either fiction or oral discourse.

Dandelion with yellow inflorescences, grasses with twigs that fly in the wind; [OTIL, II, p. 612]. This word, which expresses the writer's skill in terms of artistic and aesthetic value, metaphorical analogy, is said to refer to women whose faces, body structures are hollow and have a pleasing appearance. He didn't even look at his creamy wife. Mirmuhsin, Umid. According to Olchinbek's rate, Zubaydakhon is a unique dandelion. [K. Lightning, Hamza].

There are words in our language that seem to be created for a more figurative meaning than their original meaning.

These words, which enrich our speech, are the most accurate ratio given to the people among us, and no other word can replace this ratio. This is a phytomorphic wild mulberry. In the annotated dictionary the local mulberry, the fruit of which is seeded, black, reddish, whitish, yellowish in color; chagir tut [OTIL, IV, p. 393]. The word wild is figuratively simple, straightforward, a ratio given to people of all ranks. "Ahmad is not one of the wild kids you think he is," said Boqi. [Q. Kenja], an evening on the Mountain Road. The word hashish is also used in a figurative sense in relation to a baseless sentence. Everything he said came out in a wild voice and stiffened the neck of the assembly. [M. M. Friend, Galatepaga qaytish].

The Explanatory Dictionary of the Uzbek Language classifies a pumpkin as a perennial melon plant with large yellow flowers, trumpeted leaves, trumpet-shaped leaves, and its large crop in various forms. The large and bulging nature of the squash phytonutrient is also known as the squash, which covers the eyeball and opens and closes. His eyelids were swollen. Trying to frown. 'Tajiboy the old man was examining those who raised their hands under the eyelids with his eyes twinkling in displeasure. [P. Tursun, O'qituvchi]. Seeing the policeman's drooping eyelids and the poison dripping from his face, Matkovul was shocked. [M. Ismaili, Farg'ona tong otguncha].

The word "eyelid tax" in the figurative sense literally means to be in a state of disarray. Indeed, the phenomenon of human squashlaying and the consequent lack of mood has shifted to a change in nature as a result of the disruption of the air through metaphor. - The face of the frowning tax sky slowly began to open. [S. Anorboev, Oqsoy]. In the combination of snowfall from the eyelids, we see the opposite of the above situation, now the change in nature, that is, the snowfall moves through metaphors to situations such as extreme sadness, bitterness and depravity in man. It was snowing from the old man's eyebrows, and he was very angry. [J. Sharipov, Khorezm].

\section{CONCLUSION}

In conclusion, it is important to study metaphors as an event that is directly related to the development of our culture - an important part of the thinking of our people. The system of metaphors is formed in the language of each nation with ancient history, socio-economic, cultural and enlightenment development. Most of them are based on myths and animism. The system of metaphors is passed down from generation to generation, enriching its structure and content. Metaphors appear in direct connection with the specific traditions, customs, traditions, religious beliefs and culture of the people. The names of plants and 
animals, which are very relevant in people's daily lives and are often referred to by them, are metaphorized. The system of metaphors in language is formed in harmony with the worldview, culture and spirit of the people. In the vocabulary of the Uzbek people, many features of plants have been transferred to human nature through metaphors and have served to express a new image and content. The study of the essence of phytomorphic metaphors in a comprehensive linguoculturological aspect and the analysis of lingvopoetic features in our literature is always relevant and important for linguistics.

\section{REFERENCES}

1. AbdurahmonovX., Mahmudov N. Word aesthetics. - Tashkent: Fan, 1981. -59 p.

2. Lapasov J. Literary text and linguistic analysis. -T .: O’qituvchi, 1995.-88 p.

3. Mirtojiev M. Polysemy in the Uzbek language. - T .: Fan., - 1975. -140 p.

4. Mirtojiev $M$. Semantics in the Uzbek language. - T .: Mumtoz so'z, 2010.-288 p.

5. Mahmudov N., Khudoyberganova D. Annotated dictionary of Uzbek language analogies. -Tashkent: Manaviyat, 2013. $320 \mathrm{p}$.

6. Dictionary of Navoi's works. $-T$.: Literature and art, 1972. -791 p.

7. Sayfullayeva R., Mengliyev B., Bakiyeva G., Kurbanova M., Yunusova Z., Abuzalova M. Modern Uzbek literary language. -Tashkent: Science and technology, 2009. -415 p.

8. Annotated dictionary of the Uzbek language. I-V. -T .: National Encyclopedia of Uzbekistan, 2006-2008. T. I. 2006. -680 p .; T. II. 2006. -672 p .; T. III. 2007. -688 p .; T. IV. 2008. -608 p .; T. V. 2008. -592 p.

9. Call R. Visual aids of the Uzbek language. -T .: Fan, 1977. -187 p.

10. Razzoqov H. Uzbek folk songs // Gulyor. Fergana folk songs. Collector: $\mathrm{H}$. Razzokov. - Tashkent: Literature and Art Publishing House, 1967. - pp.236-251 